\title{
Response analysis of piping system with collision characteristics
}

Aoki S. ${ }^{(1)}$, Watanabe T. ${ }^{(2)}$

(1) Tokyo Metropolitan College of Technology, Japan

(2) Yamanashi University, Japan

\begin{abstract}
This paper deals with steady-state response of a piping system with nonlinear support which are motion-limiting constraint. Considering the energy loss in a collision, an analytical method of approximate solution for the continuous system with asymmetrical and symmetrical hysteresis loop characteristics in which the beam end collides with the nonlinear support once and twice in one period of its vibration is presented. Some numerical results of the approximate solution are shown.
\end{abstract}

\section{INTRODUCTION}

The forced response of piping system with nonlinear supports which are motion-limiting constraints or clearances is of great importance for the nonlinear vibration problem concerning piping systems in nuclear power plants and others[1]-[3]. Sufficiently accurate knowledge of the system response, for a given set of nonlinear parameters concerning the support, also helps in designing and controlling the system and avoiding unacceptable levels of vibration. In analysis of such systems, analytical model with bilinear restoring force characteristics in which stiffness increases after collision is generally used[4],[5]. On the other hand, there is energy loss in a collision which is represented by coefficient of restitution. However, few papers on vibraton analysis of the continuous system with collision taking account of energy loss have been published. Modelling of energy loss in a collision is carried out by assuming hysteresis loop characteristics in relation between force of restitution and penetration[6].

In this paper, analytical methods of approximate steady-state solution for the piping system with asymmetrical and symmetrical hysteresis loop characteristics in which the beam end collides with the nonlinear support once and twice in one period of its vibration, respectively, are presented. In these methods, force of restitution is expanded into Fourier series. Some numerical results of resonance curves for the system with asymmetrical and symmetrical hysteresis loop characteristics are shown.

Next, analytical methods of approximate steady-state solution for the piping system without hysteresis loop characteristics are obtained. Some numerical results of resonance 
curvess are shown.

The objectives of this paper are to provide the reader the methods of the approximate steady-state solution of the continuous system with asymmetrical and symmetrical collision characteristics under harmonic excitation and to show the numerical results of the approximate solution for designing the piping system.

\section{ANALYTICAL METHOD FOR THE SYSTEM WITH HYSTERESIS LOOP CHARACTERISTICS}

\subsection{System with asymmetrical collision characteristics}

A simplified dynamical model of the continuous system with asymmetrical collision characteristics is shown in Fig.1. Namely, this model consists of a beam clamped at one end, with one-sided amplitude constraint by the nonlinear support having hysteresis loop characteristics (Fig.2) at the other end.

Let $\rho$ be the mass density, A the cross-sectional area, and EI the modulus of flexural rigidity. The equation for transverse free vibration of a beam can be written as follows:

$$
\frac{\partial^{2} \mathrm{y}}{\partial \mathrm{t}^{2}}+\frac{\mathrm{EI}}{\rho \mathrm{A}} \frac{\partial^{4} \mathrm{y}}{\partial \mathrm{x}^{4}}=0
$$

The relations between $\mathrm{y}$ and $\mathrm{z}$ as shown in Fig. 1 are given by

$$
\mathrm{y}=\mathrm{z}+\mathrm{y} \circ \cos \omega \mathrm{t}
$$

Hence we have

$$
\frac{\partial^{2} \mathrm{z}}{\partial \mathrm{t}^{2}}+\frac{\mathrm{EI}}{\rho \mathrm{A}} \frac{\partial^{4} \mathrm{z}}{\partial \mathrm{x}^{4}}=\mathrm{y} \circ \omega^{2} \cos \omega \mathrm{t}
$$

Assuming the solution for Eq.(1) as

$$
y=\sum_{n=1}^{\infty} X_{n}(x) \cos n \omega t
$$

a formal solution of Fq.(3) can be expressed as follows:

$$
\begin{aligned}
\mathrm{z}= & -\mathrm{y} 0 \cos \omega \mathrm{t}+\sum_{\mathrm{n}=1}^{\infty}\left(\mathrm{A}_{\mathrm{n}} \cosh \lambda_{\mathrm{n}} \mathrm{x}+\mathrm{B}_{\mathrm{n}} \sinh \lambda_{\mathrm{n}} \mathrm{x}\right. \\
& \left.+\mathrm{C}_{\mathrm{n}} \cos \lambda_{\mathrm{n}}+\mathrm{D}_{\mathrm{n}} \sin \lambda_{\mathrm{n}} \mathrm{x}\right) \cos \omega_{\mathrm{t}}
\end{aligned}
$$

where $A_{n}, B_{n}, C_{n}, D_{n}$ are constants to be determined in each particular case from the boundary conditions of the beam, where

$$
\lambda_{\mathrm{n}}{ }^{4} /^{4}=\mathrm{Z}_{1}{ }^{4} \mathrm{n}^{2} \Omega_{1}{ }^{2}, \quad \Omega_{1}=\omega / \omega_{1}
$$

and

$$
\omega_{1}=\frac{Z_{1}^{2}}{l^{2}} \sqrt{\frac{E I}{\rho A}}, \quad Z_{1}=1.8751
$$

The boundary conditions for this case are as follows:

$$
\begin{aligned}
& \text { 1) } x=0, \quad z=0 \\
& \text { 2) } x=0, \frac{d z}{d x}=0 \\
& \text { 3) } x=\iota, \frac{d^{2} z}{d x^{2}}=0
\end{aligned}
$$




$$
\text { 4) } \mathrm{x}=\iota, \quad \mathrm{EI} \frac{\mathrm{d}^{3} \mathrm{z}}{\mathrm{dx}^{3}}=\mathrm{f}(\mathrm{z} \iota, \dot{\mathrm{z}} \iota)
$$

where $\mathrm{z} I$ is the transverse displacement at the beam end $(x=d)$ and the nonlinear shearing force $\mathrm{f}\left(\mathrm{z}_{1}, \dot{\mathrm{z}}_{1}\right)$ is defined by the following piecewise-linear characteristics as shown in Fig.2:

$$
\begin{aligned}
& \mathrm{f}\left(\mathrm{z}_{1}, \mathrm{z}_{1}\right)=\mathrm{K}_{1}\left(\mathrm{z}_{1} \mathrm{e}_{0}-\mathrm{e}_{0}\right) \\
& \mathrm{f}\left(\mathrm{z}, \dot{\mathrm{z}}_{1}\right)=\mathrm{K}_{2}\left(\begin{array}{llll}
\mathrm{z}_{1} & -\mathrm{z} & 13
\end{array}\right) \\
& ; \quad \mathrm{z}_{1} \geqq \mathrm{e} 0, \quad \dot{\mathrm{z}}_{1} \geqq 0 \quad(\mathrm{I}) \\
& \mathrm{f}\left(\mathrm{z}_{1}, \dot{\mathrm{z}}_{1}\right)=0 ; \mathrm{z}_{1} \leqq \mathrm{z}_{13}, \mathrm{z}_{1} \leqq 0 \text { and } \mathrm{z}_{1} \leqq \mathrm{e} 0, \mathrm{z}_{1} \geqq 0
\end{aligned}
$$

where $\mathrm{K}_{1}$ and $\mathrm{K}_{2}$ are the spring constants of the nonlinear support at the beam end as shown in Fig. 2 and $\mathrm{e} o$ is a clearance. Displacement at the beam end of the interval (II) $\mathrm{Z} 13$ is written as follows:

$$
\mathrm{z}_{13}=\mathrm{e}_{0}+\left(1-\frac{\mathrm{K}_{1}}{\mathrm{~K}_{2}}\right)(\mathrm{z} \text { Imax }-\mathrm{e} 0)
$$

where $\mathrm{z} \mathrm{Im}_{\mathrm{m}} \mathrm{x}$ denotes the maximum displacement at the beam end.

Employig the equations of boundary conditions (8) and (9), Eq.(5) can be reduced to

$z=y_{0}\left(\cos \lambda_{1} \mathrm{x}-1\right) \cos \omega \mathrm{t}$

$$
+\sum_{n=1}^{\infty}\left\{A_{n}\left(\cosh \lambda_{n} x-\cos \lambda_{n} x\right)+B_{n}\left(\sinh \lambda_{n} x-\sin \lambda_{n} x\right)\right\} \cos n \omega t
$$

And then, from Eq.(14) with the boundary condition equation (10), the following equations will be obtained:

$$
\left(\cosh \lambda_{1} \ell+\cos \lambda_{1} \ell\right) \mathrm{A}_{1}+\left(\sinh \lambda_{1} \ell+\sin \lambda_{1} \ell\right) \mathrm{B}_{1}=\mathrm{y} 0 \cos \lambda_{1} \ell, \quad(\mathrm{n}=1)
$$

$\left(\cosh \lambda_{\mathrm{n}} \ell+\cos \lambda_{\mathrm{n}} \ell\right) \mathrm{A}_{\mathrm{n}}+\left(\sinh \lambda_{\mathrm{n}} \ell+\sin \lambda_{\mathrm{n}} \ell\right) \mathrm{B}_{\mathrm{n}}=0$,

In this paper, the steady-state vibration is dealt with for the case in which the beam end collides with the nonlinear support once in one period of its vibration. Once the impact vibration becomes steady and periodic, the nonlinear shearing force $f\left(z_{1}, \dot{z}_{1}\right)$ becomes also periodic and can be represented as a periodic functin $\mathrm{g}(\theta)$ of $\theta$ with the period $2 \pi$. And $\theta$ is defined by the following equation:

$$
\theta=\omega \mathrm{t}-\alpha
$$

where $\alpha$ is the phase lag angle.

This periodic function $\mathrm{g}(\boldsymbol{\theta})$ must satisfy the conditions of the given characteristics of the nonlinear shearing force equation (12), which is, in this case, to be written as the following equations:

$$
\begin{aligned}
& \mathrm{f}\left(\mathrm{z}_{1}, \dot{\mathrm{z}}_{1}\right)=\mathrm{g}(\theta)=\mathrm{K}_{1}\left(\mathrm{z}_{1}-\mathrm{e} 0\right) ;-\theta 1 \leqq \theta \leqq 0 \\
& \mathrm{f}\left(\mathrm{z}_{1}, \dot{\mathrm{z}}_{1}\right)=\mathrm{g}(\theta)=\mathrm{K}_{2}\left(\mathrm{z}_{1}-\mathrm{z}_{13}\right) ; 0 \leqq \theta \leqq \theta_{2} \\
& \mathrm{f}\left(\mathrm{z}_{1}, \mathrm{z}_{1}\right)=\mathrm{g}(\theta)=0 \quad ; \theta_{2} \leqq \theta \leqq 2 \pi-\theta_{1}
\end{aligned}
$$

where $\theta_{1}$ and $\theta_{2}$ denote the range of the phase angle $\theta$ during the period of the contact of the beam end with the nonlinear support. In the foregoing, one period $2 \pi$ of the resulting vibration is divided into three intervals. During the first and the second intervals of length $\theta_{1}$ and $\theta_{2}$, respectively, the beam end moves in contact as shown in Fig.3. And during the third interval of length $2 \pi-\left(\theta_{1}+\theta_{2}\right)$, the beam end moves without contact.

Introducing a Fourier series expansion for the periodic function $\mathrm{g}(\theta)$ as

$$
g(\theta)=\frac{a_{0}}{2}+\sum_{n=1}^{\infty}\left(a_{n} \cos n \theta+b_{n} \sin n \theta\right)
$$

In this paper, let the function $\mathrm{g}(\theta)$ be approximated by 


$$
\mathrm{g}(\theta)=\frac{\mathrm{a} o}{2}+\mathrm{a}_{1} \cos \theta+\mathrm{b}_{1} \sin \theta
$$

As shown in referece [7], when $g(\theta)$ is approximated by only the fundamental term of the Fourier expansion, approximate solution agree with exact solution for relatively small nonlinear parameter $\left(\mathrm{K}_{1} / \mathrm{k}\right.$ and $\left.\mathrm{K}_{2} / \mathrm{k}\right)$ used in this paper.

Thus, from Eq.(14) with the last equation of boundary conditin (11), the following equation is derived:

$\left(\sinh \lambda_{1} \ell-\sin \lambda_{1} \ell\right) \mathrm{A}_{1}+\left(\cosh \lambda_{1} \ell+\cos \lambda_{1} \ell\right) \mathrm{B}_{1}$

$$
=\frac{\frac{\mathrm{a}_{0}}{2}+\mathrm{a}_{1} \cos \theta+\mathrm{b}_{1} \sin \theta}{\mathrm{EI} \lambda_{1}{ }^{3} \cos (\theta+\alpha)}-\mathrm{y}_{0} \sin \lambda_{1} \ell
$$

Neglecting the higher order terms than $n=1$, the formal solution Eq.(14) with the aid of Eq.(15) and Eq.(16) yields to the following equation:

$$
\begin{aligned}
\mathrm{z}= & \mathrm{y}_{0}\left(\cos \lambda_{1 \mathrm{x}}-1\right) \cos (\theta+\alpha) \\
& +\left\{\mathrm{A}_{1}\left(\cosh \lambda_{1 \mathrm{x}} \cos \lambda_{1 \mathrm{x}}\right)+\mathrm{B}_{1}\left(\sinh \lambda_{1 \mathrm{x}}-\sin \lambda_{1 \mathrm{x}}\right)\right\} \cos (\theta+\alpha)
\end{aligned}
$$
where

$\mathrm{A}_{1}=\mathrm{y}_{0}\left(1+\cosh \lambda_{1} \ell \cos \lambda_{1} \ell+\sinh \lambda_{1} \ell \sin \lambda_{1} \ell\right) / \Delta_{1}$

$$
-\frac{\frac{\mathrm{a} 0}{2}+\mathrm{a}_{1} \cos \theta+\mathrm{b}_{1} \sin \theta}{\mathrm{EI} \lambda_{1}{ }^{3} \Delta_{1} \cos (\theta+\alpha)}\left(\sinh \lambda_{1} \ell+\sin \lambda_{1} \ell\right)
$$

$\mathrm{B}_{1}=-\mathrm{y}_{0}\left(\cosh \lambda_{1} \ell \sin \lambda_{1} \ell+\sinh \lambda_{1} \ell \cos \lambda_{1} \ell\right) / \Delta_{1}$

$$
\begin{gathered}
+\frac{\frac{\mathrm{a} 0}{2}+\mathrm{a}_{1} \cos \theta+\mathrm{b}_{1} \sin \theta}{\mathrm{EI} \lambda_{1}{ }^{3} \Delta_{1} \cos (\theta+\alpha)}\left(\cosh \lambda_{1} \ell+\cos \lambda_{1} \ell\right) \\
\Delta_{1}=2\left(1+\cosh \lambda_{1} \ell \cos \lambda_{1} \ell\right)
\end{gathered}
$$

Then, displacement of beam end $z$, is

$$
\mathrm{z}_{\iota}=\mathrm{y}_{\circ} \mathrm{N}_{\iota} \cos (\theta+\alpha)+\mathrm{M}_{1} \frac{\mathrm{a}_{0}}{2 \mathrm{k}}+\mathrm{M}_{1} \frac{\mathrm{a}_{1}}{\mathrm{k}} \cos \theta+\mathrm{M}_{1} \frac{\mathrm{b}_{1}}{\mathrm{k}} \sin \theta
$$

where

$$
\begin{aligned}
& \mathrm{k}=\frac{3 \mathrm{EI}}{\ell^{3}} \\
& \mathrm{~N}_{\iota}=\frac{\left(1-\cos \lambda_{1} \ell\right)\left(\cosh \lambda_{1} \ell-1\right)}{1+\cosh \lambda_{1} \ell \cos \lambda_{1} \ell} \\
& \mathrm{M}_{1}=\frac{3 \lambda_{1} \ell}{\mathrm{Z}_{1}{ }^{4} \Omega_{1}{ }^{2}} \frac{\left(\cos \lambda_{1} \ell \sinh \lambda_{1} \ell-\cosh \lambda_{1} \ell \sin \lambda_{1} \ell\right)}{\left(1+\cosh \lambda_{1} \ell \cos \lambda_{1} \ell\right)}
\end{aligned}
$$

Meanwhile the switching-over conditions from one to another of the three intervals ( $I$ ), ( II ) and ( II ) are expressed by

$$
\begin{array}{lc}
\theta=-\theta_{1}, \mathrm{z}_{\iota}=\mathrm{e}_{0} & (\mathrm{III} \rightarrow \mathrm{I}) \\
\theta=0, \mathrm{z}_{\iota}=0, \mathrm{z}_{\iota}=\mathrm{z}_{\iota \mathrm{max}} & (\mathrm{I} \rightarrow \mathrm{II}) \\
\theta=\theta_{2}, \mathrm{z}_{\iota}=\mathrm{z}_{\iota 3} . & (\mathrm{II} \rightarrow \text { II })
\end{array}
$$

Eqation(26) can be written as follows: 


$$
\mathrm{z}_{1}=\left(\mathrm{y}_{0} \mathrm{~N}_{1} \cos \alpha+\mathrm{M}_{1} \frac{\mathrm{a} 1}{\mathrm{k}}\right) \cos \theta+\mathrm{M}_{1} \frac{\mathrm{a} 0}{2 \mathrm{k}}
$$

Introducing $\Gamma$ and $\mathrm{c}$ as

$$
\begin{aligned}
& \Gamma=\mathrm{y}_{\circ} \mathrm{N}_{1} \cos \alpha+\mathrm{M}_{1 \mathrm{k}}^{\mathrm{a}_{1}}=\frac{\mathrm{e}_{0}}{\cos \theta_{1}}-\frac{\mathrm{M}_{1} \mathrm{a}_{0}}{2 \mathrm{k} \cos \theta_{1}} \\
& \mathrm{c}=\mathrm{M}_{1} \frac{\mathrm{a} o}{2 \mathrm{k}}
\end{aligned}
$$

Equation(33) is to be reduced to

$$
\mathrm{z}_{t}=\Gamma \cos \theta+\mathrm{c}
$$

And the nondimensional Fourier coefficients are defined as follows:

$$
\mathrm{x}_{0}=\frac{\mathrm{a}_{0}}{\mathrm{k} \Gamma}, \mathrm{x}_{1}=\frac{\mathrm{a}_{1}}{\mathrm{k} \Gamma}, \mathrm{y}_{1}=\frac{\mathrm{b}_{1}}{\mathrm{k} \Gamma}
$$

Then,

$$
\mathrm{z}_{I}=\Gamma\left(\cos \theta+\frac{1}{2} \mathrm{M}_{1} \mathrm{x}_{0}\right)
$$

From Eqs.(34), (37), (38) and (30)-(32), the amplitude of the beam end $\Gamma$, the phase lag angle $\alpha$ and the amplitude y o of sinusoidal excitation are determined as:

$$
\begin{aligned}
& \frac{\Gamma}{\mathrm{e}_{0}}=\frac{\mathrm{y}_{0}}{\mathrm{e}_{0}} \frac{\mathrm{N}_{1}}{\sqrt{\left(1-\mathrm{M}_{1} \mathrm{x}_{1}\right)^{2}+\left(\mathrm{M}_{\left.1 \mathrm{y}_{1}\right)^{2}}\right.}} \\
& \alpha=\tan ^{-1}\left(\frac{M_{1} y_{1}}{1-M_{1} x_{1}}\right) \\
& \frac{\mathrm{y}_{0}}{\mathrm{e}_{0}}=\frac{1}{\cos \theta_{1}+\mathrm{M}_{1} \mathrm{x}_{0} / 2} \frac{\sqrt{\left(1-\mathrm{M}_{1} \mathrm{x}_{1}\right)^{2}+\left(\mathrm{M}_{1} \mathrm{y}_{1}\right)^{2}}}{\mathrm{~N}_{1}}
\end{aligned}
$$

Since the function $\mathrm{g}(\theta)$ in Eq.(18) has been approximated by Eq.(20), the piecewise-linear characteristics expressed by Eq.(18) of nonlinear shearing force, combined with Eq.(38), can be approximately written as follows:

$$
\begin{aligned}
\frac{\mathrm{g}(\theta)}{\mathrm{k} \Gamma}= & \frac{\mathrm{x}_{0}}{2}+\mathrm{a}_{1} \cos \theta+\mathrm{b}_{1} \sin \theta \\
= & \frac{\mathrm{K}_{1}}{\mathrm{k}}\left(\cos \theta-\cos \theta_{1}\right) ;-\theta_{1} \leqq \theta \leqq 0 \\
\frac{\mathrm{g}(\theta)}{\mathrm{k} \Gamma}= & \frac{\mathrm{x}_{0}}{2}+\mathrm{a}_{1} \cos \theta+\mathrm{b}_{1} \sin \theta \\
= & \frac{\mathrm{K}_{2}}{\mathrm{k}}\left(\cos \theta-\cos \theta_{2}\right) ; 0 \leqq \theta \leqq \theta_{2} \\
\frac{\mathrm{g}(\theta)}{\mathrm{k} \Gamma}= & \frac{\mathrm{x}_{0}}{2}+\mathrm{a}_{1} \cos \theta+\mathrm{b}_{1} \sin \theta=0 \\
& ; \theta_{2} \leqq \theta \leqq 2 \pi-\theta_{1}
\end{aligned}
$$

Applying a technique similar to that for determinig Fourier coefficients, namely, multiplying both sides of Eq.(42) by $1, \cos \theta$ and $\sin \theta$ and integrating through the whole period of $2 \pi$, the nondimensional coefficients $\mathrm{x}_{0}, \mathrm{x}_{1}$ and $\mathrm{y}_{1}$ are obtained as follws: 


$$
\begin{aligned}
& \mathrm{x}_{0}=\frac{1}{\pi}\left\{\frac{\mathrm{K}_{1}}{\mathrm{k}}\left(\sin \theta_{1}-\theta_{1} \cos \theta_{1}\right)+\frac{\mathrm{K}_{2}}{\mathrm{k}}\left(\sin \theta_{2}-\theta_{2} \cos \theta_{2}\right)\right\} \\
& \mathrm{x}_{1}=\frac{1}{\pi}\left\{\frac{\mathrm{K}_{1}}{\mathrm{k}}\left(\frac{\theta_{1}-\sin \theta_{1} \cos \theta_{1}}{2}\right)+\frac{\mathrm{K}_{2}}{\mathrm{k}}\left(\frac{\theta_{2}-\sin \theta_{2} \cos \theta_{2}}{2}\right)\right\} \\
& \mathrm{y} 1_{1}=\frac{1}{\pi}\left\{\frac{\mathrm{K} 1}{\mathrm{k}}\left(\frac{1}{2} \sin ^{2} \theta_{1}-1+\cos \theta_{1}\right)-\frac{\mathrm{K}_{2}}{\mathrm{k}}\left(\frac{1}{2} \sin ^{2} \theta_{2}-1+\cos \theta_{2}\right)\right\}
\end{aligned}
$$

Assuming that $\theta_{1}$ and $\theta_{2}$ are small, $\mathrm{x}_{0}, \mathrm{x}_{1}$ and $\mathrm{y}_{1}$ are approximately given by

$$
\begin{aligned}
& \mathrm{x}_{0}=\frac{1}{3 \pi} \frac{\mathrm{K}_{1} / \mathrm{k} \cdot \mathrm{K}_{2} / \mathrm{k}}{\left(\sqrt{\mathrm{K}_{1} / \mathrm{k}}+\sqrt{\mathrm{K}_{2} / \mathrm{k}}\right)^{2}} \theta_{0}{ }^{3} \\
& \mathrm{x}_{1}=\frac{1}{3 \pi} \frac{\mathrm{K}_{1} / \mathrm{k} \cdot \mathrm{K}_{2} / \mathrm{k}}{\left(\sqrt{\mathrm{K}_{1} / \mathrm{k}}+\sqrt{\mathrm{K}_{2} / \mathrm{k}}\right)^{2}} \theta_{0}{ }^{3} \\
& \mathrm{y}_{1}=\frac{1}{8 \pi} \frac{\mathrm{K}_{1} / \mathrm{k} \cdot \mathrm{K}_{2} / \mathrm{k} \cdot\left(\mathrm{K}_{1} / \mathrm{k}_{2} \mathrm{~K}_{2} / \mathrm{k}\right)}{\left(\sqrt{\mathrm{K}_{1} / \mathrm{k}}+\sqrt{\mathrm{K}_{2} / \mathrm{k}}\right)^{4}} \theta_{0}{ }^{4}
\end{aligned}
$$

where $\theta$ o denotes the range of the phase angle $\theta$ duration the period of the contact of the beam end with the nonlinear support, and $\theta_{1}$ and $\theta_{2}$ are expressed as follows:

$$
\begin{aligned}
& \theta_{1}=\frac{\sqrt{\mathrm{K}_{2} / \mathrm{k}}}{\sqrt{\mathrm{K}_{1} / \mathrm{k}}+\sqrt{\mathrm{K}_{2} / \mathrm{k}}} \theta_{0} \\
& \theta_{2}=\frac{\sqrt{\mathrm{K}_{1} / \mathrm{k}}}{\sqrt{\mathrm{K}_{1} / \mathrm{k}}+\sqrt{\mathrm{K}_{2} / \mathrm{k}}} \theta_{0}
\end{aligned}
$$

From Eqs.(46), (47) and (48), Eq.(39) and Eq.(41) can be written as follows:

$$
\begin{aligned}
& \frac{\Gamma}{\mathrm{e}_{0}}=\frac{\mathrm{y}_{0}}{\mathrm{e}_{0}} \frac{\mathrm{N}_{1}}{\sqrt{\left(1-\mathrm{M}_{1} \mathrm{X} \theta_{0}{ }^{3}\right)^{2}+\left(\mathrm{M}_{1} \mathrm{Y}_{\left.\theta_{0}{ }^{4}\right)^{2}}\right.}} \\
& \frac{\mathrm{y}_{0}}{\mathrm{e}_{0}}=\frac{1}{1-\theta_{1}{ }^{2} / 2+\mathrm{M}_{1} \mathrm{x}_{0} / 2} \frac{\sqrt{\left(1-\mathrm{M}_{1} \mathrm{X}_{1}\right)^{2}+\left(\mathrm{M}_{1} \mathrm{y}_{1}\right)^{2}}}{\mathrm{~N}_{1}} \\
& =\frac{1}{1-\mathrm{W} \theta_{0}{ }^{2} / 2+\mathrm{M}_{1} \mathrm{X}_{\theta_{0}{ }^{3} / 2}} \frac{\sqrt{\left(1-\mathrm{M}_{1} \mathrm{X}_{\left.0_{0}\right)^{3}+\left(\mathrm{M}_{1} \mathrm{Y}_{0_{0}}\right)^{2}}\right.}}{\mathrm{N}_{1}}
\end{aligned}
$$

where

$$
\begin{aligned}
& \mathrm{X}=\frac{1}{3 \pi} \frac{\mathrm{K}_{1} / \mathrm{k} \cdot \mathrm{K}_{2} / \mathrm{k}}{\left(\sqrt{\mathrm{K}_{1} / \mathrm{k}}+\sqrt{\mathrm{K}_{2} / \mathrm{k}}\right)^{2}} \\
& \mathrm{Y}=\frac{1}{8 \pi} \frac{\mathrm{K}_{1} / \mathrm{k}^{2} \cdot \mathrm{K}_{2} / \mathrm{k} \cdot\left(\mathrm{K}_{1} / \mathrm{k}^{-\mathrm{K}_{2} / \mathrm{k}}\right)}{\left(\sqrt{\mathrm{K}_{1} / \mathrm{k}}+\sqrt{\mathrm{K}_{2} / \mathrm{k}}\right)^{4}} \\
& \mathrm{~W}=\left(\frac{\sqrt{\mathrm{K}_{2} / \mathrm{k}}}{\sqrt{\mathrm{K}_{1} / \mathrm{k}}+\sqrt{\mathrm{K}_{2} / \mathrm{k}}}\right)^{2}
\end{aligned}
$$

Fixing the parameter $\Omega_{1}, \theta 0$ can be obtained from the following equation derived by Eq.(52) for a given value of $\mathrm{y}_{2} \circ / \mathrm{e}_{2}$.

$$
\begin{aligned}
& \theta_{0}{ }^{8}+\left\{1-\frac{1}{4}\left(\frac{\mathrm{y}_{0}}{\mathrm{e}_{0}} \mathrm{~N}_{1}\right)\right\}\left(\frac{\mathrm{X}}{\mathrm{Y}}\right)^{2} \theta_{0}{ }^{6}+\frac{1}{2}\left(\frac{\mathrm{y}_{0} \mathrm{~N}_{1}}{\mathrm{e}_{0}}\right)^{2} \frac{\mathrm{WX}}{\mathrm{M}_{1} \mathrm{Y}^{2}} \theta_{0}{ }^{5} \\
& -\frac{1}{4}\left(\frac{\mathrm{y}_{0}}{\mathrm{e}_{0}} \mathrm{~N}_{1}\right) \frac{\mathrm{W}^{2}}{\left(\mathrm{M}_{1} \mathrm{Y}^{2}\right.} \theta_{0}{ }^{4}-\left\{2+\left(\frac{\mathrm{y}_{0}}{\left.\left.\mathrm{e}_{\mathrm{o}} \mathrm{N}_{1}\right) \cdot\right\}} \frac{\mathrm{X}}{\mathrm{M}_{1} \mathrm{Y}^{2}} \theta_{0}{ }^{3}\right.\right.
\end{aligned}
$$




$$
+\left(\frac{\mathrm{y}_{0}}{\mathrm{e}_{\mathrm{o}}} \mathrm{N}_{1}\right)^{2} \frac{\mathrm{W}}{\left(\mathrm{M}_{1} \mathrm{Y}^{2}\right.} \theta_{0}{ }^{2}+\left\{1-\left(\frac{\mathrm{y}_{0}}{\mathrm{e}_{\mathrm{o}}} \mathrm{N}_{1}\right)^{2}\right\} \frac{1}{\left(\mathrm{M}_{1} \mathrm{Y}\right)^{2}}=0
$$

Then, $\Gamma / \mathrm{e} o$ can be obtained, utilizing Eq.(51).

\subsection{System with symmetrical collision characteristics}

For the symmetrical system with hysteresis loop characteristics shown in Fig.4, Eq.(20) is written as:

$$
\mathrm{g}(\theta)=\mathrm{a}_{1} \cos \theta+\mathrm{b}_{1} \sin \theta
$$

And Eq.(53) and (54) are expressed as:

$$
\begin{aligned}
& \mathrm{X}=\frac{2}{3 \pi} \frac{\mathrm{K}_{1} / \mathrm{k} \cdot \mathrm{K}_{2} / \mathrm{k}}{\left(\sqrt{\mathrm{K}_{1} / \mathrm{k}}+\sqrt{\mathrm{K}_{2} / \mathrm{k}}\right)^{2}} \\
& \mathrm{Y}=\frac{1}{4 \pi} \frac{\mathrm{K}_{1} / \mathrm{k} \cdot \mathrm{K}_{2} / \mathrm{k} \cdot\left(\mathrm{K}_{1} / \mathrm{k}-\mathrm{K}_{2} / \mathrm{k}\right)}{\left(\sqrt{\mathrm{K}_{1} / \mathrm{k}}+\sqrt{\mathrm{K}_{2} / \mathrm{k}}\right)^{4}}
\end{aligned}
$$

Eq. (52) is written as:

$$
\frac{\mathrm{y}_{0}}{\mathrm{e}_{0}}=\frac{1}{1-\mathrm{W} \theta_{0}^{2} / 2} \frac{\sqrt{\left(1-\mathrm{M}_{1} \mathrm{X}_{\theta_{0}}^{3}\right)^{2}+\left(\mathrm{M}_{1} \mathrm{Y}_{\left.0_{0}^{4}\right)^{2}}\right.}}{\mathrm{N}_{1}}
$$

Fixing the parameter $\Omega_{1}, \theta$ can be obtained from Eq.(60) for a given value of y o / 0 . Then, $\Gamma$ /e o can be obtained, utilizing Eq.(51).

\section{ANALYTICAL METHOD FOR THE SYSTEM WITHOUT HYSTERESIS LOOP CHARACTERISTICS}

\subsection{System with asymmetrical collision characteristics}

For the asymmetrical system without hysteresis loop characteristics, the nonlinear force of restitution $\mathrm{f}\left(\mathrm{z}_{1}\right)$ of the system with asymmetrical collision characteristics shown in Fig. 1 is defined by the following piecewise-linear characteristics as shown in Fig.5:

$$
\begin{aligned}
& \mathrm{f}(\mathrm{z} \iota)=\mathrm{K}(\mathrm{z} \iota-\mathrm{e} 0) ; \mathrm{z} \iota \geqq \mathrm{e} 0 \quad(\mathrm{I}) \\
& \mathrm{f}(\mathrm{z} 1)=0 ; \mathrm{z}_{1} \leqq \mathrm{e}_{0} \quad \text { ( II ) }
\end{aligned}
$$

where $\mathrm{K}$ is the spring constants of the stop at the beam end as shown in Fig.5.

The periodic function $\mathrm{g}(\theta)$ must satisfy the conditions of the given characteristics of the nonlinear force of restitution equation (61), which is, in this case, to be written as the following equations:

$$
\begin{aligned}
& \mathrm{f}(\mathrm{z}, \mathrm{l})=\mathrm{g}(\theta)=\mathrm{K}(\mathrm{z},-\mathrm{e} o \mathrm{o}) ;-\frac{\theta_{\mathrm{o}}}{2} \leqq \theta \leqq \frac{\theta_{0}}{2} \\
& \mathrm{f}\left(\mathrm{z}_{1}\right)=\mathrm{g}(\theta)=0 \quad ; \frac{\theta_{0}}{2} \leqq \theta \leqq 2 \pi-\frac{\theta_{0}}{2} \quad \text { ( II ) }
\end{aligned}
$$

where $\theta_{0}$ denotes the range of the phase angle $\theta$ during the period of the contact of the beam end with the nonlinear support at one side as shown in Fig.6.

In this paper, let the function $\mathrm{g}(\theta)$ be approximated by 


$$
g(\theta)=\frac{\mathrm{a}_{0}}{2}+\mathrm{a}_{1} \cos \theta
$$

The amplitude of the beam end $\Gamma$ and the amplitude $\mathrm{y}$ o of sinusoidal excitation are determined as:

$$
\begin{aligned}
& \frac{\Gamma}{\mathrm{e}_{0}}=\frac{\mathrm{y}_{0}}{\mathrm{e}_{0}} \frac{\mathrm{N}_{1}}{1-\frac{\mathrm{M}_{1}}{12 \pi} \frac{\mathrm{K}}{\mathrm{k}} \theta_{0}{ }^{3}} \\
& \frac{\mathrm{y} 0}{\mathrm{e}_{0}}=\frac{1-\frac{\mathrm{M}_{1}}{12 \pi} \frac{\mathrm{K}}{\mathrm{k}} \theta_{0}{ }^{3}}{\mathrm{~N}_{1}\left\{\left(1-\frac{\theta_{0}{ }^{2}}{8}\right)+\frac{\mathrm{M}_{1}}{24 \pi} \frac{\mathrm{K}}{\mathrm{k}} \theta_{0}{ }^{3}\right\}}
\end{aligned}
$$

Fixing the parameter $\Omega_{1}, \theta_{0}$ can be obtained from the following equation derived by equation (65) for a given value of $\mathrm{y} o / \mathrm{e} 0$.

$$
\left(\frac{\mathrm{M}_{1}}{24 \pi} \frac{\mathrm{K}}{\mathrm{k}} \frac{\mathrm{yo}}{\mathrm{e}_{0}} \mathrm{~N}_{1}+\frac{\mathrm{M}_{1}}{12 \pi} \frac{\mathrm{K}}{\mathrm{k}}\right) \theta_{0}{ }^{3}-\frac{1}{8} \frac{\mathrm{y}_{0}}{\mathrm{e}_{0}} \mathrm{~N}_{\iota} \theta_{0}{ }^{2}+\frac{\mathrm{yo}_{\mathrm{o}}}{\mathrm{e}_{\mathrm{o}}} \mathrm{N}_{1-1}-0
$$

Then, utilizing equation (66), $\Gamma$ /e o can be obtained.

\subsection{System with symmetrical collision characteristics}

For the symmetrical system without hysteresis loop characteristics, Eq.(63) is written as:

$$
g(\theta)=\mathrm{a}_{1} \cos \theta
$$

The amplitude of the beam end $\Gamma$ and the amplitude $\mathrm{y}$ o of sinusoidal excitation are determined as:

$$
\begin{aligned}
& \frac{\Gamma}{\mathrm{e}_{0}}=\frac{\mathrm{y}_{0}}{\mathrm{e}_{0}} \frac{\mathrm{N}_{1}}{1-\frac{\mathrm{M}_{1}}{6 \pi} \frac{\mathrm{K}}{\mathrm{k}} \theta_{0}{ }^{3}} \\
& \frac{\mathrm{y} o_{0}}{\mathrm{e}_{0}}=\frac{1-\frac{\mathrm{M}_{1}}{6 \pi} \frac{\mathrm{K}}{\mathrm{k}} \theta_{0}{ }^{3}}{\mathrm{~N}_{1}\left(1-\frac{\theta_{0}{ }^{2}}{8}+\frac{\theta_{0}^{4}}{384}\right)}
\end{aligned}
$$

Fixing the parameter $\Omega_{1}, \theta_{0}$ can be obtained from the Eq.(69) for a given value of $y_{0}$ /e 0 . Then, utilizing equation (68), $\Gamma / \mathrm{e} 0$ can be obtained.

\section{NUMERICAL EXAMPLES}

\subsection{Results of the system with hysteresis loop characteristics}

Figures 7 and 8 show resonance curves of the system with asymmetrical collision characteristics with the amplitude $\Gamma / \mathrm{e}_{0}$ of the beam end versus the frequency ratio $\Omega_{1}$ obtained by the method of approximate solution utilizing a digital computer in which 
several exciting ratios y o/e o are taken to be constant. Figures 7 (a) and 7(b) show resonance curves for $y_{0} / e_{0}=1.0$ and 0.5 of a system with low ratio of nonlinear parameter $\mathrm{K}_{1} / \mathrm{k}=3$ and $\mathrm{K}_{2} / \mathrm{k}=10$. Figure 8 shows resonance curves of the system with high ratio of nonlinear parameter $\mathrm{K}_{1} / \mathrm{k}=10$ and $\mathrm{K}_{2} / \mathrm{k}=30$. The resonance curves of nonlinear response of approximate solution are shown as discontinuous line. In the discontinuous region, the periodic solution can not be obtained. From Fig.7 and Fig.8, it is clear that the region depends on the nonlinear parameter $\mathrm{K}_{1} / \mathrm{k}$ and $\mathrm{K}_{2} / \mathrm{k}$. For $\mathrm{y}_{0} / \mathrm{e}_{0}$, as $\mathrm{y}_{0} / \mathrm{e}_{0}$ decreases, $\Gamma / \mathrm{e}_{0}$ decreases. The effect of $\mathrm{y} o / \mathrm{e}_{0}$ on discontinuous region is less than nonlinear parameters.

Figures 9 and 10 show resonance curves of the system with symmetrical collision characteristics. In this case, resonance curves are shown as continuous curves.

\subsection{Results of the system without hysteresis loop characteristics}

Figures 11 and 12 show resonance curves of continuous system with asymmetrical collision characteristics. For comparing the results of the system with hysteresis loop characteristics, $\mathrm{K}_{1} / \mathrm{k}$ is taken to be equal to $\mathrm{K} / \mathrm{k}$. The resonance curves of nonlinear response of approximate solution are also shown as discontinuous line. In the discontinuous region, the periodic solution can not be obtained. Comparing Fig.10 with Fig.7 or Fig. 11 with Fig.8, discontinuous regions are wider than those of the system with hysteresis loop characteristics. Since energy is not dissipated, resonance curves tend to infinite at resonance frequency.

Figure 13 shows resonance curves of the system with symmetrical collision characteristics. In this case, resonance curves are shown as continuous curves.

\section{CONCLUSIONS}

An approximate solution for the steady-state response of continuous system with asymmetrical and symmetrical collision characteristics in which the beam end collides with the nonlinear support once and twice in one period of its vibration has been proposed. Resonance curves are obtained for several exciting ratios y o / 0 of the systems with low and high ratio of nonlinear parameter $\mathrm{K}_{1} / \mathrm{k}$ and $\mathrm{K}_{2} / \mathrm{k}$ or $\mathrm{K} / \mathrm{k}$ by applying the approximate solution. For the system with asymmetrical collision characteristics, the resonance curves of nonlinear response of approximate solution are shown as discontinuous line. In the discontinuous region, the periodic solutions can not be obtained. It is clear that the discontinuous region depends on the nonlinar parameters $\mathrm{K}_{1} / \mathrm{k}$ and $\mathrm{K}_{2} / \mathrm{k}$ or $\mathrm{K} / \mathrm{k}$. This is especially noteworthy, it may be connected with chaotic vibration. The discontinuous region of the resonance curves of continuous system without hysteresis loop characteristics is wider than that with hysteresis loop characteristics.

Stability problems and random excitation problems of these continuous systems will be discussesd in the forthcoming papers by the authors.

Finally, the authors would like to acknowledge their deep appreciation for the valuable suggestions given to this work by Professor Emeritus Heki Shibata of the Unversity of Tokyo. 


\section{REFERENCES}

1. Watanabe,T. 1978. Forced vibration of continuous system with nonlinear boundary conditions. Trans. of ASME, Journal of Mechanical Design 100. 487-491.

2. Moon,F.C. and Shaw,S.W. 1883. Chaotic vibrations of a beam with nonl-inear boundary conditions. International Joumal of Non-linear Mechanics. 18-.6. p.465-477.

3. Shaw,S.W.1985. Forced vibrations of a beam with one-sided amplitude constraint:Theory and experiment. Journal of Sound and Vibration. 99-2. 199-212.

4. Lin,C.W. 1991. Seismic evaluation of systems and components. Trans. of ASME, Journal of pressure Vessel Technology. 113 May. 273-283.

5. Worner, J.D. 1989. Determination of ultimate aseismic strength of equipment and piping. Proc. of ASME PVP-182. 155-158.

6. Aoki,S. and Watanabe,T. 1993. Forced vibration of continuous system with unsymmetrical hysteresis loop characteristics. Proceedings of Asis-Pacific Vibration Conference 1680-1685.

7. Watanabe,T and Shibata.H. 1981. On nonlineear vibration os a beam - Response of a beam with a gap at one end - . Report of the Institute of Industrial Science The University of Tokyo.24-187. 1-25.

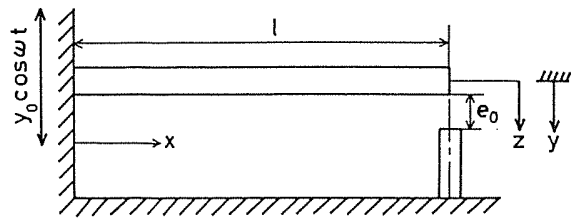

Fig. 1 Analytical model of continuous system with asymmetrical collision characteristics

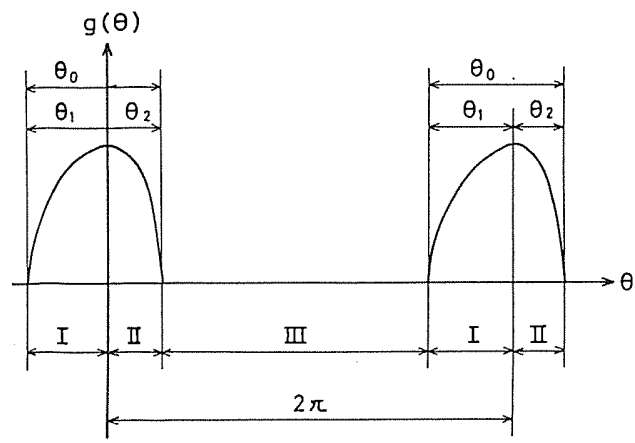

Fig. 3 Waveform of force of restitution at beam end

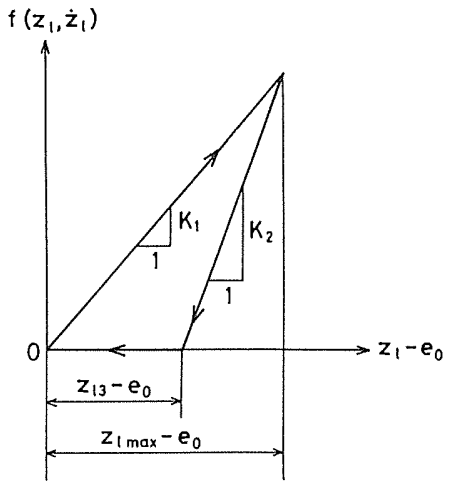

Fig. 2 Hysteresis loop characteristics of force of restitution at the beam end

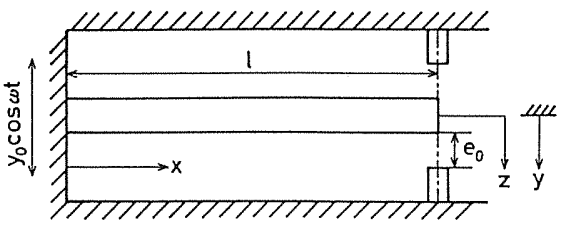

Fig.4 Analytical model of continuous system with symmetrical collision characteristics 


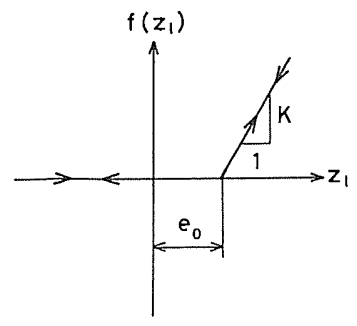

Fig. 5 Relation between force of restitution and penetration

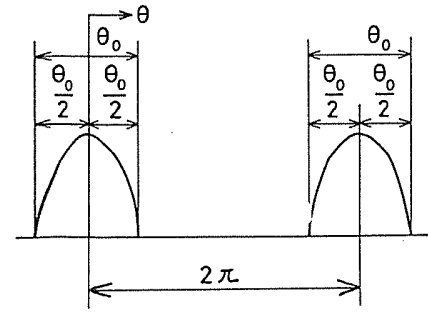

Fig.6 Waveform of force of restitution at beam end

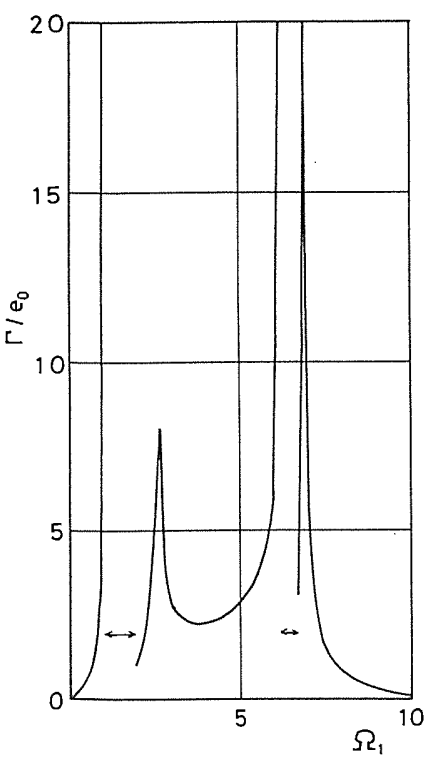

Fig. 8 Resonance curve of continuous system with asymmetrical collision characteristics $\left(\mathrm{K}_{1} / \mathrm{k}=10\right.$ $\mathrm{K}_{2} / \mathrm{k}=30$, y o $/ \mathrm{e}_{0}=1.0$ )

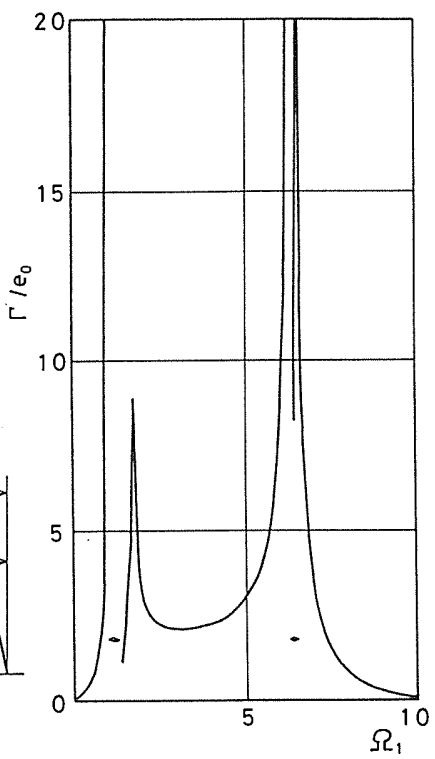

(a) $\mathrm{y}_{0} / \mathrm{e} 0=1.0$

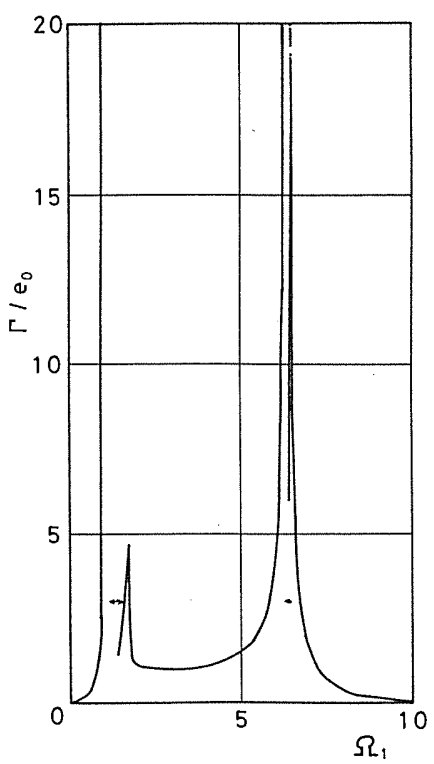

(b)y o $/ \mathrm{e}_{0}=0.5$

Fig.7 Resonsnce curve of continuous system with asymmetrical collision characteristics $\left(\mathrm{K}_{1} / \mathrm{k}=3, \mathrm{~K}_{2} / \mathrm{k}=10\right)$

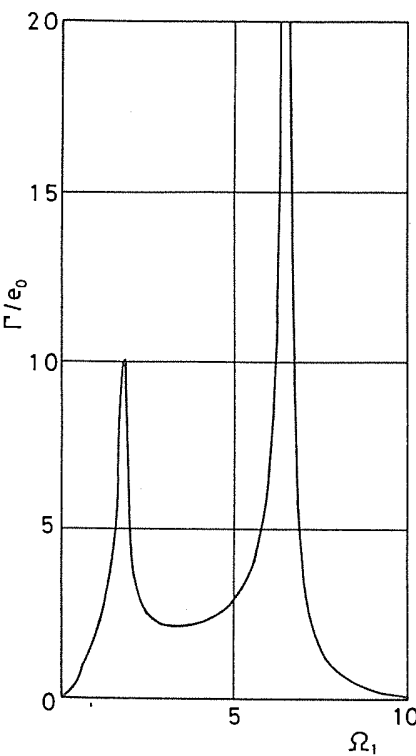

Fig.9 Resonsnce curve of continuous system with symmetrical collision characteristics $\left(\mathrm{K}_{1} / \mathrm{k}=3\right.$, $\mathrm{K}_{2} / \mathrm{k}=10$, y o $/ \mathrm{e}_{0}=1.0$ )

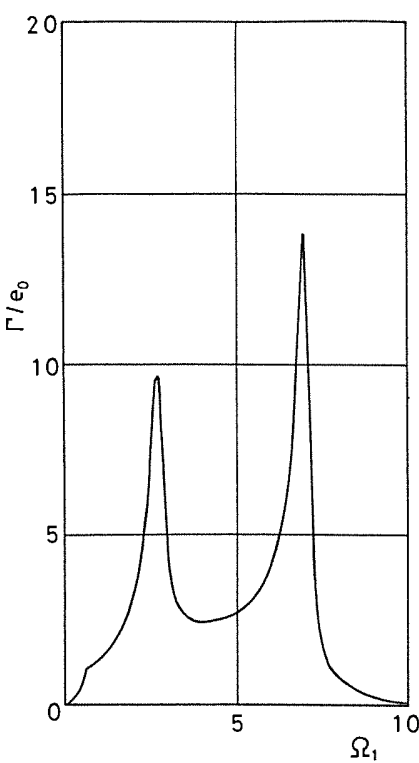

Fig. 10 Resonance curve of continuous system with symmetrical collision characteristics $\left(\mathrm{K}_{1} / \mathrm{k}=10\right.$, $\mathrm{K}_{2} / \mathrm{k}=30, \mathrm{y}$ o $/ \mathrm{e}_{0}=1.0$ ) 


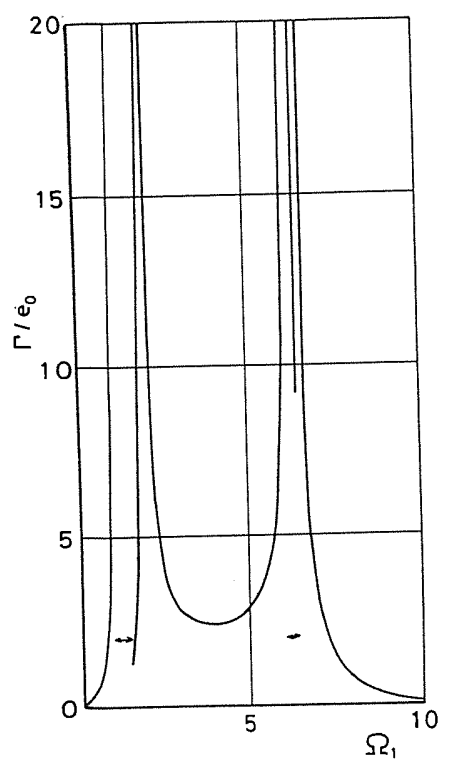

(a) $\mathrm{y}_{0} / \mathrm{e} 0=1.0$

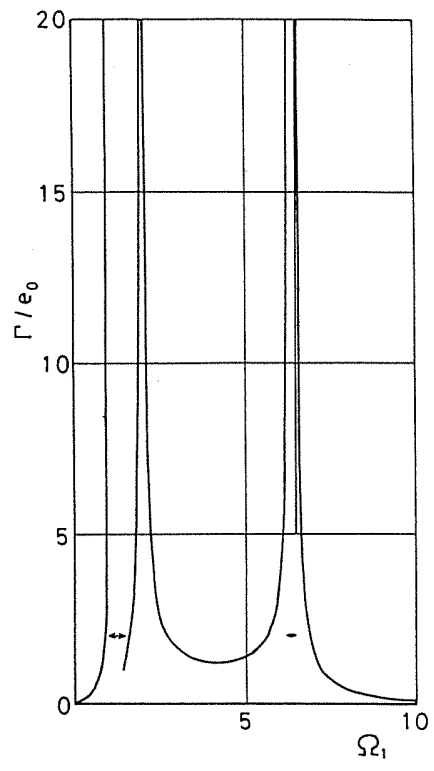

(b) $\mathrm{y}_{0} / \mathrm{e} 0=0.5$

Fig.11 Resonsnce curve of continuous system with asymmetrical collision characteristics

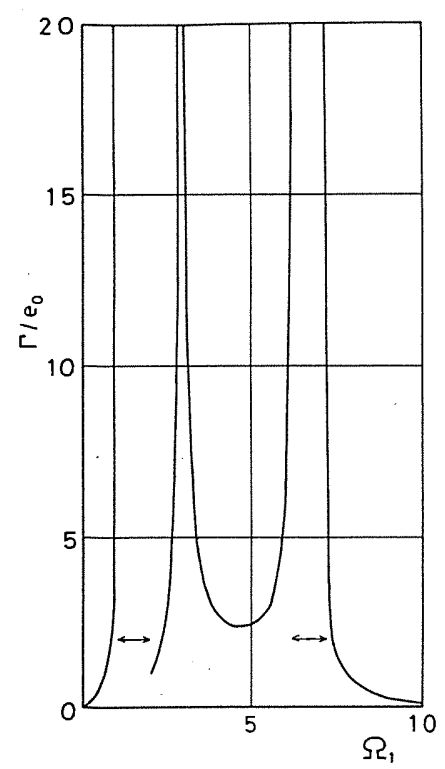

Fig. 12 Resonance curve of continuous system with asymmetrical collision characteristics

$\left(\mathrm{K} / \mathrm{k}=10\right.$, y $\left.0 / \mathrm{e}_{0}=1.0\right)$

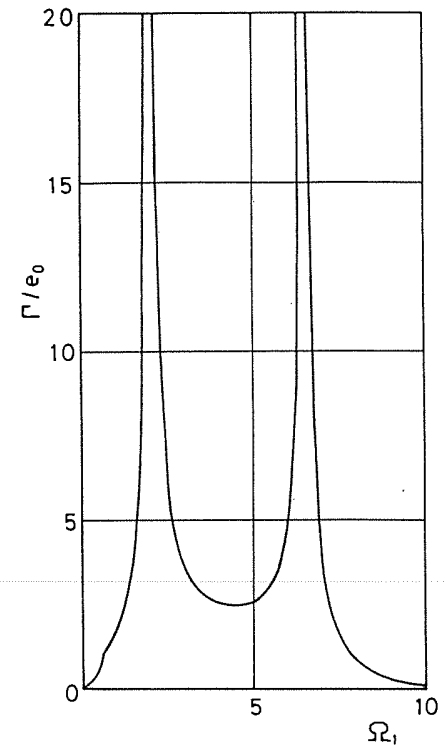

Fig.13 Resonsnce curve of continuous system with symmetrical collision characteristics

$\left(\mathrm{K} / \mathrm{k}=3\right.$, y o $\left./ \mathrm{e}_{0}=1.0\right)$ 